\title{
Pediatric Cardiac Surgery In Eritrea.
}

A retrospective analysis of 300 cardiac patients operated, 2002-2008.

Tsegereda Gebrehiwot MD1, Yoseph Tewolde MD2

Institutional affiliation of the authors

1 Pediatrician, Orotta Pediatric National Referral Hospital, Asmara, Eritrea

2 General Surgeon, Halibet Hospital, Asmara, Eritrea

\section{Abstract}

A review of pediatric cardiac operations performed in the International Operation Center for Children in Asmara (IOCCA) between 2002 and 2008 was made. A total of 300 patients underwent corrective cardiac procedures during the time specified. Out of these, $273(91 \%)$ were patients suffering from congenital heart defects while the rest $27(9 \%)$ had acquired heart diseases. The female to male ratio was $1.4: 1$, and $157(52 \%)$ patients were under five years of age. $188(63 \%)$ of the procedures were open heart operations using the heart lung-machine and $112(37 \%)$ were closed heart operations without the cardiopulmonary bypass. The commonest operations performed were for PDA 103(34\%), while the commonest open heart surgery was for VSD 74(25\%). The mortality rate for patients operated was $7(2.3 \%)$ and the re-operation rate was $5(1.7 \%)$.

The presence of an organized pediatric cardiac service in the country and its role in addressing different cardiac defects surgically and minimizing the cost of the procedures done elsewhere is emphasized.

\section{Introduction}

Worldwide, the incidence of congenital heart defects is approximately one out of every 100 children born annually, and nearly one-third of these require surgery in the first year of life. Without treatment, 20\% of these children will die within the first few weeks of life (1).

Medical and surgical services for children with congenital and acquired heart disease in most industrialized countries are easily available and all inclusive, regardless of the cost. In many parts of the world, nevertheless, children with similar types of cardiac disease continue to be unable to achieve entrée to adequate diagnosis and care $(2,3)$.

Rheumatic heart disease is still an important heart disease in many parts of the world especially among the rural poor. WHO surveys in 1970 \& 1980s and institutional reviews in 1990s showed an extremely high incidence of rheumatic fever \& rheumatic heart disease in the developing countries. Nearly 400,000 deaths occur due to RF and its heart complications (3).

Surgical correction of congenital and acquired heart defects has been in practice in an organized manner in Eritrea since 2002. The history of cardiac surgery however dates back to 1998, when a Swiss cardiac team performed the first open heart Surgery using the heart-lung machine for correction of a valvular heart defect. Since then a humanitarian organization from Germany, the Hammer Forum team started to develop and renovate a modern surgical center for cardiac operations within the premises of Orotta hospital. In 2002 an International Operation Center for Children in Asmara (IOCCA) was inaugurated, where cardiac operations for pediatric patients are provided.

In an attempt to study the pattern of pediatric cardiac operations performed in Eritrea and outcomes of therapy, a retrospective study was undertaken in IOCCA from 2002 to 2008.

\section{Materials and Methods}

We reviewed all the records of pediatric cardiac operations performed in IOCCA between 2002 and 2008. Medical records including information on age, gender, demography, type of heart defects and treatment offered with surgical outcomes was retrieved.

Diagnosis was primarily made clinically based on the history of presentation and physical examination findings. Laboratory tests and other diagnostic modalities including echocardiography done in the cardiac follow up clinic of Orotta pediatric referral hospital was an important aid to define the cardiac abnormalities.

Patients were prioritized for surgical treatment upon the urgency of the clinical situation during screening and time of follow up. Treatment outcomes and results were defined upon the follow up of patients in the cardiac clinic. Postoperative patients were also regularly followed by the visiting cardiac team for any residual problems or other complications.

\section{Results}

A total of 300 patients were operated for congenital and acquired cardiac defects between 2002 and 2008. The female to male ratio was $1.4: 1$. The mean age at surgery was 6.5 years (1month-18 years) and $157(52 \%)$ patients were children under 5 years of age (Table 1 ).

Table 1: Age and sex distribution of Cardiac patients Operated, $2002-2008$

\begin{tabular}{|l|l|l|l|}
\hline AGE & FEMALE & MALE & TOTAL \\
\hline $0-1 \quad$ Year & 22 & 21 & 43 \\
\hline $1-5$ Years & 67 & 47 & 114 \\
\hline$>5 \quad$ Years & 86 & 57 & 143 \\
\hline Total & 175 & 125 & 300 \\
\hline
\end{tabular}


The majority of the procedures were open heart operations using the cardiopulmonary bypass $188(63 \%)$ while the rest $112(37 \%)$ were closed heart operations (Table 2). Six patients were re-operated for surgical complications and the hospital mortality for patients operated was $7(2.3 \%)$.

\begin{tabular}{|c|c|c|c|}
\hline TYPE & FEMALE & MALE & TOTAL \\
\hline OPEN & 98 & 90 & 188 \\
\hline CLOSED & 77 & 35 & 112 \\
\hline TOTAL & 175 & 125 & 300 \\
\hline
\end{tabular}

Most open cardiac operations were performed for patients with ventricular septal defects $74(25 \%)$ while the majority of closed heart operations were for patent ductus arteriosus 103(34\%)

Table 3: Types of lesions of cardiac patients operated, 2002-2008

\begin{tabular}{|l|c|c|c|}
\hline TYPES & FEMALE & MALE & TOTAL \\
\hline PDA & 73 & 30 & 103 \\
\hline VSD & 35 & 39 & 74 \\
\hline ASD & 31 & 27 & 58 \\
\hline TOF & 7 & 11 & 18 \\
\hline PS & 8 & 3 & 11 \\
\hline COA & 4 & 5 & 9 \\
\hline AS+/- AR & 3 & - & 3 \\
\hline ASD + VSD & 3 & 2 & 5 \\
\hline TGA & 1 & & 1 \\
\hline MR +/- MS & 9 & 4 & 13 \\
\hline Others & 2 & 3 & 5 \\
\hline
\end{tabular}

Among the patients operated $179(60 \%)$ were from outside the vicinity of Zoba Maekel and all Zobas were almost uniformly represented (Figure 1)

Figure 1: Geographical distribution of cardiac patients operated, 2002-2008

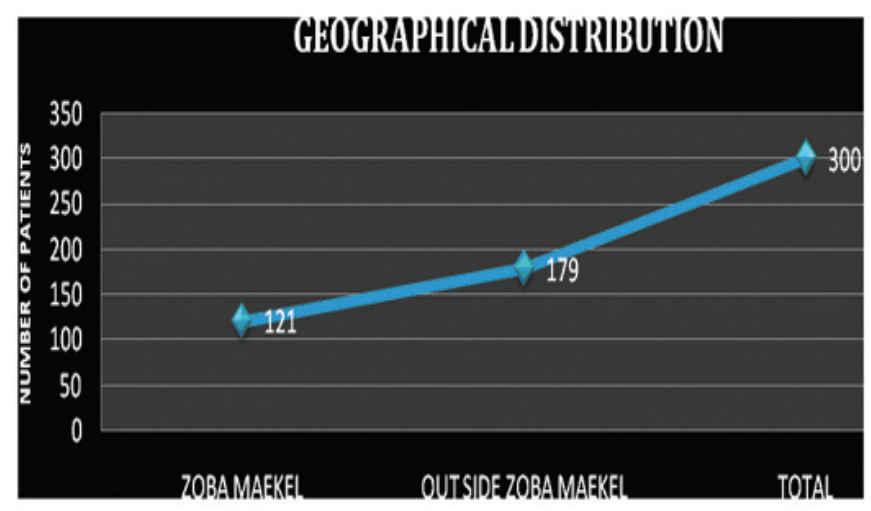

The number of operations has increased progressively with the increase in the number of surgical missions to the country. There were five surgical missions in 2008 providing a total of 70 cardiac operations (Figure 2)

The number of operations has increased progressively with the increase in the number of surgical missions to the country. There were five surgical missions in 2008 providing a total of 70 cardiac operations (Figure 2)

Figure 2: Trends of operations every year, 2002-2008.

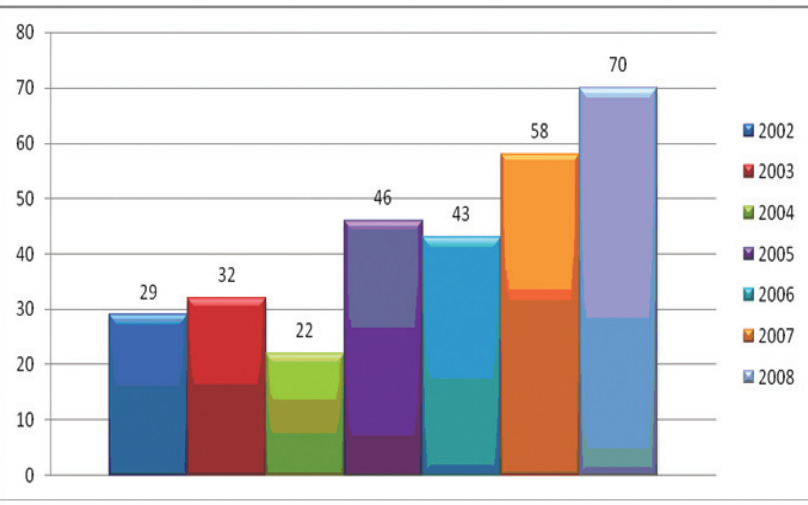

A number of countries in the developing world do not have adequate services for the care of children with cardiac diseases. The requirement for clinical services and education in pediatric cardiovascular disease is however critical (5). The first humanitarian cardiovascular surgical mission in Eritrea was organized in April of 2002. A total of 22 missions provided 300 cardiac operations between 2002 \& 2008. The teams consisted of volunteer physicians from Germany, Italy and Switzerland including cardiac surgeons, pediatric cardiologists, cardiac anesthesiologists, pediatric intensivists, perfusionists, and other nursing staff. Each mission has routinely included at least 18 health professionals of different category to maximize the quality of the medical services provided. This has been shown to decrease the rate of surgical complications which occurred in only $10(3 \%)$ patients and the low hospital mortality rate $7(2.3 \%)$ which has profoundly bettered several other similar missions in different developing countries (6).

The intended purpose of the humanitarian program was to provide pediatric cardiac operations, staff education, clinical services, and the development of an organized independent cardiac service team in Eritrea. Providing operations in the country reduces at large morbidity and mortality and also decreases the total average cost per child \& decreases travel costs to the parents \& provides them with a similar cultural environment. Parents are far less anxious when they are in a similar environment during the stressful time associated with cardiac surgery on their children. The cost effectiveness of the surgical mission has been justified by the fact that the money spent for one open heart surgery in Europe can be used to treat at least 15 children in Eritrea avoiding all the social barriers described. It has been proved that sustainability of an expensive mission of such magnitude can only be maintained when the host country is quite committed to the service and this has played a greater role in assuring the funding organizations and volunteer 
physicians to increase the number of missions over the years (7).

The surgical missions have provided a substantial pediatric cardiovascular service to Eritrean children with congenital and acquired heart diseases with reasonable surgical outcomes which are comparable to many developed countries. They have also contributed to an enormous financial savings. The service has however some limitations at present in providing operations for complex cardiac lesions because of lack of cardiac catheterization, which is in the process of construction, and a permanent intensive care unit for prolonged hospitalization. The latter is also a hindrance for not having many patients operated with acquired heart diseases.

In conclusion this study has emphasized the magnitude of the problem in Eritrean children and the measures undertaken to provide the most complex procedures in the country. It has also made clear the commitment of the country in developing an organized independent pediatric cardiac program in collaboration with friendly partners. The unit is also hoped to provide fully functioning independent cardiac service in the near future. Last but not least the need to install and maintain a comprehensive centralized database for cardiac surgical results remains.

\section{Acknowledgements}

The authors would like to acknowledge every member of the pediatric cardiac unit in IOCCA involved in the management and well being of children operated in Eritrea. Our gratitude also goes to the Hammer Forum Cardiac surgery unit and the Italian Pediatric cardiac Surgery unit from Padova for their humanitarian assistance and without whom this establishment would have been impossible. We also acknowledge the Ministry of health of Eritrea for giving priority to this expensive but successful establishment and for providing all the required assistance.

\section{References}

1. Cohen AJ, Tamir A, and Houri S, et al. Save a child's heart: we can and we should. Ann Thorac surg 2001; 71: 462-468.

2. Heart surgery in underdeveloped countries; success in Panama and Romania. Ann Thoac surg 1993; 56: 14391440.

3. Congenital heart disease outcome analysis; methodology and rational. J Thorac cardiovasc surg 2002; 123: 6-7.

4. International pediatric cardiac assistance in Croatia: results of the 10 year program: Croat Med J 2004; 45:389-395.

5. Novic WM, Gurbiz AT, Watson DC, Lazorishinets VV, Perpeka AN, et al. Double patch closure of VSD with increased pulmonary vascular resistance. Ann Thorac surg. 1998; 66:1533-8.

6. Jenkins KJ, Newburger JW, Lock JE, Davis RB, Coffmann GA, Lezzoni LI. In-hospital mortality for surgical repair of congenital heart defects; preliminary observations by hospital caseloads. Pediatrics. 1995; 95: 323-30.

7. Chang AC. How to start and sustain a successful cardiac intensive care program: A combined clinical and administrative strategy. Pediatr Crit Care Med. 2002; 3:10711.

8. Surgery for congenital heart defects. J Stark, M. de Leval and VT Tsang. 2006. 